\title{
Posição dos partidos políticos relativamente às pessoas idosas - Comparação Portugal e Espanha
}

\author{
Preciosa Maria Taveira Lousada \\ UNIVERSIDADE DE SANTIAGO DE COMPOSTELA, SANTIAGO DE COMPOSTELA, ESPANHA \\ preciosa.lousada@gmail.com
}

Resumo: Este artigo versa sobre a posição dos partidos políticos relativamente às pessoas idosas, comparando Portugal e Espanha, recorrendo aos dados do Manifesto Research Group/Comparative Manifesto Project (MP). Analisam-se os programas eleitorais das eleições portuguesas de 1999 a 2011 (principais partidos que compõem o arco de governação) e eleições espanholas de 2000 a 2015 (partidos de âmbito estatal). Genericamente, a esquerda em Portugal e esquerda/centro-esquerda em Espanha assumem a preponderância na defesa da expansão do Estado de bem-estar e população idosa, por oposição aos partidos do centro/centro-direita que evidenciam uma orientação menos favorável neste domínio.

Palavras-Chave: partidos políticos, expansão do Estado de bem-estar, retração do Estado de bem-estar, pessoas idosas, escala esquerda-direita

Abstract: This article examines political parties' positions as regards the elderly, comparing Portugal and Spain, and by using data of the Manifesto Research Group/Comparative Manifesto Project (MP). The electoral programs issued for the Portuguese elections from 1999 to 2011 are examined along with the manifestos of the Spanish state-wide parties from 2000 to 2015. Generally speaking, the left in Portugal and the left/centre-left in Spain, in opposition to the parties located at the centre/centre-right, are in favour of giving priority to the defence of both the expansion of the Welfare-State and social protection for the elderly.

Keywords: political parties, welfare State expansion, social retrenchment, elderly, left-right scale.

\section{Introdução}

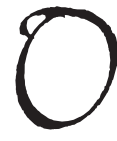

futuro das sociedades democráticas contemporâneas está hoje na ordem do dia, face à presença de complexas transformações que apelam à redefinição dos pressupostos contratuais que estiveram na génese do Estado-Providência do pós-guerra.

Congrega bastante consensualidade a constatação de que as políticas sociais atuais, modeladas, de modo geral, por condicionalismos estruturais e pelo discurso da austeridade, defrontam barreiras e fronteiras quanto à sua propensão integradora e revestem prescrições traiçoeiras da matriz essencial do bem-estar social. 
No âmago deste cenário arrevesado, de ameaça da coesão social e das políticas sociais presentes, emergem interpelações relacionadas com os alicerces do próprio Estado social e com o seu rumo. Todavia, a complexidade e profundidade que as políticas sociais abrangem deixam antever a dificuldade de uma abordagem transversal à totalidade dos seus pilares.

Deste modo, e porque o século XX ficou marcado por importantes transformações na estrutura etária das populações, com uma reconfiguração demográfica jamais conhecida, urge a procura de respostas e soluções adaptadas às novas necessidades, repensando o papel dos idosos nas sociedades e as políticas públicas dirigidas ao envelhecimento.

Como refere Ares (2018), o envelhecimento da população é um processo demográfico natural, inerente às sociedades desenvolvidas, relacionado com o aumento da percentagem de pessoas com idade igual ou superior a 65 anos sobre o total da população mundial.

As alterações demográficas integram o leque dos designados Novos Riscos Sociais (NRS), afigurando-se como um desafio à atuação dos Estados de Bem-estar. Segundo Moreno (2012:30) Los câmbios societários, [...] son identificados [...] como las principales causas en la aparición de los nuevos riesgos sociales. Todavia, os programas concebidos para os enfrentar foram questionados pela crise de 2007/2008, sendo que alguns governos, a coberto dela, e perante pressões de índole financeira, introduziram cortes em programas pouco consolidados (Pino e Lara: 2013, Eds.). A Equipa NorSpar (2015: 12) salienta: El aumento en el número absoluto y relativo de personas mayores implica tanto una creciente demanda de cuidado como una importante presión económica.

A efervescência desta nova realidade dita a formulação, não apenas do aprofundamento de estudos de conhecimento do fenómeno, efeitos e antecipação de cenários, como também conhecer o impacto que esta problemática desencadeia no seio do pensamento político/candidatos ao poder, razão que fundamenta e legitima o presente estudo e o seu objetivo central, isto é avaliar a posição dos partidos políticos relativamente às pessoas idosas, tanto na ótica da expansão como de retração do Estado social, procurando responder às questões: quais os partidos que maior número de referências favoráveis/desfavoráveis apresentam em defesa do Estado social; existe alguma relação entre a posição na escala esquerda-direita (Rile) e o nível de defesa do Estado social (Welfare State) de cada partido político; os temas abordados nos manifestos eleitorais dos partidos, em ambos os países, são convergentes ou divergentes e, ainda, se a relação entre a posição na escala esquerda-direita (Rile) e os níveis de defesa do Estado social (Welfare State) de cada partido, em ambos os países, é igual ou distinta. 
A escolha dos partidos políticos, quer em Portugal (partidos que compõem o arco de governação) quer em Espanha (partidos de âmbito estatal) deveu-se, no essencial, ao protagonismo que recolhem no seio do eleitorado. Neste último caso, acrescentaram-se ao estudo algumas coligações e uma força política com formação muito recente (Podemos), no sentido de avaliar se os seus discursos continham elementos diferenciadores.

A opção pela comparação Portugal - Espanha teve na sua base singularidades como a pertença à União Europeia, a proximidade geográfica, a integração no grupo de quatro países habitualmente incluídos no modelo de Estado de Bem-estar mediterrâneo Familista e, ainda, o seu percurso histórico-político marcado por um longo período de governação sob orientação ditatorial.

À semelhança de outros, estes países foram atingidos pela crise económico-financeira de 2007/2008 (embora com peculiaridades próprias) e comungam o Novo Risco Social do envelhecimento da população e os desafios que ele representa para as sociedades, constituindo argumento suficiente para as agendas sociopolíticas neste domínio.

Apesar desta homogeneidade de características, e centrando a atenção na população idosa, interessa perceber como os distintos partidos, nos seus territórios, no quadro dos seus princípios doutrinais, percecionam a realidade social, que preocupações ostentam e que soluções oferecem nos seus manifestos eleitorais, viabilizando, deste modo, a confrontação de estratégias partidárias (mostrar semelhanças e diferenças), posições ideológicas e apoiando a partilha de soluções políticas para problemas que podem ter denominadores comuns. Para além disto, este estudo poderá servir de base a análises comparadas dinâmicas (evolução ao longo dos vários períodos eleitorais), permitindo aos eleitores a tomada de decisões mais apoiadas e conscientes.

Acresce que os resultados aqui alcançados poderão despertar o interesse por investigações futuras, seja através do aprofundamento desta temática (avaliando o nível de concretização das intenções plasmadas nos manifestos dos partidos e, consequentemente, o impacto na vida dos cidadãos), seja pela aplicação desta mesma metodologia de investigação a outras áreas da proteção social.

Para a concretização deste estudo recorreu-se ao Manifesto Project ${ }^{1}$, enquanto método de análise de conteúdo codificada e quantificada das posições dos partidos políticos em diversas eleições, de vários países membros da Organização para a Cooperação e Desenvolvimento Económico (OCDE).

1. Projeto erigido nos anos 70 com o propósito de comparar as estratégias programáticas dos partidos nos Estados Unidos e Reino Unido, durante o período posterior à II Guerra Mundial. 


\section{A metodologia do Manifesto Project (MP) ${ }^{2}$}

A metodologia de base ao MP é a análise de conteúdo dos programas eleitorais concebidos por cada uma das forças políticas no sentido de alcançar as suas orientações ideológicas. Cada proposta de programa mais não é do que uma forma de os partidos se apresentarem ao seu eleitorado.

A referida análise traduz uma técnica de investigação que faz uma radiografia das mensagens políticas viabilizando deduções de apreciado valor, passíveis de reprodução. Trata-se, pois, de uma técnica consolidada para determinar as posições dos partidos no espaço político, disponibilizando resposta a diversas questões de investigação.

Para o tratamento da informação contida nos vários programas eleitorais, o MP baseia-se num esquema de classificação standard ${ }^{3}$ (56 categorias), constituído por distintas áreas, às quais correspondem diversos códigos numéricos, conforme exemplo da tabela 1. Dentro deste esquema foi selecionada a área 5 (Bem-estar e qualidade de vida), códigos numéricos 504 (Expansão do Estado de bem-estar) e 505 (Retração do Estado de bem-estar).

Tabela 1

Exemplo da classificação standard do Manifesto Research in Political Representation

\begin{tabular}{l}
\hline Área 5 - Bem-estar Social e Qualidade de Vida \\
\hline 503 - Justiça Social: Positivo \\
\hline 504 - Expansão do Estado de bem-estar \\
\hline 505 - Retração do Estado de bem-estar \\
\hline 506 - Expansão da Educação \\
\hline 507 - Retração da Educação \\
\hline \hline
\end{tabular}

Fonte: Elaboração própria com base em Alonso; Volkens e Gomez (2012).

Em termos práticos, cada texto programático é fragmentado em quase-frases, posteriormente codificadas dentro da área correspondente. A partir desta segmentação é possível calcular a relevância, isto é a percentagem de referências que cada

2. Segundo a opinião de vários investigadores, o MP é a referência empírica mais utilizada no estudo dos partidos políticos, possibilitando a análise da evolução das suas posições nos confrontos eleitorais.

3. O MP conta com 56 categorias padrão. Segundo Alonso; Volkens e Gomez (2012) cada uma das categorias e subcategorias do sistema de codificação do MP pode ser entendida como um indicador de uma preferência concreta que determinado partido dá a conhecer aos eleitores. 
categoria recebe num determinado programa eleitoral. A escolha da categoria ou categorias a estudar resulta das questões de investigação, às quais o investigador quer responder.

A operacionalização deste estudo baseou-se, numa primeira etapa, na recolha de todas as frases codificadas com o código 504 e 505, com posterior seleção das que fazem unicamente menção às pessoas idosas, por país, ato eleitoral e partido político, seguindo-se, para ambos os códigos, uma análise qualitativa das referidas frases.

O estudo realizado consistiu, então, na análise quantitativa e qualitativa das frases categorizadas com os códigos 504 e 505, constantes dos programas eleitorais dos partidos selecionados, nos anos eleitorais definidos. Efetuou-se, de igual modo, para os dois países e períodos eleitorais, o estudo da posição dos partidos políticos na escala esquerda-direita e o nível de defesa do Estado de bem-estar.

Assim, numa primeira fase, desenvolve-se uma apresentação gráfica abreviada da análise quantitativa para cada um dos países individualmente considerados e, de seguida, dada a extensão do estudo qualitativo, uma síntese comparativa da análise qualitativa dos dois países.

\section{Apresentação gráfica - Estudo quantitativo}

Portugal - A expansão do Estado de bem-estar

\section{Gráfico 1}

Expansão do Estado de Bem-estar - Referências favoráveis à sua defesa Atos Eleitorais/Partidos Políticos

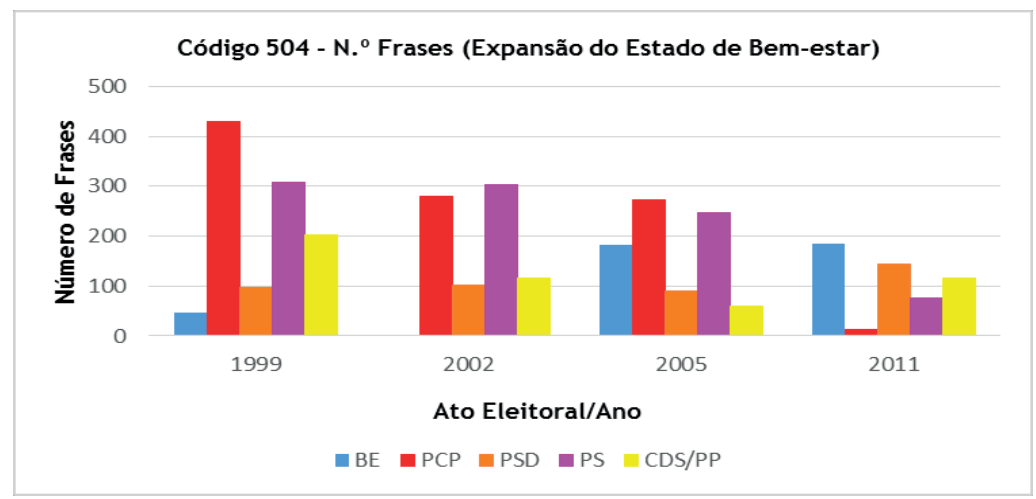

Fonte: Elaboração própria com base nos datos do Manifest Project 
A representação gráfica indica o número de frases encontradas nos manifestos eleitorais dos partidos políticos ${ }^{4} \mathrm{BE}, \mathrm{PCP}, \mathrm{PSD}, \mathrm{PS}$ e CDS/PP, em quatro atos eleitorais: 1999, 2002, 2005 e 2011, ${ }^{5}$ categorizadas com o código 504 (Expansão do Estado de bem-estar).

No ato eleitoral de 1999, a força política que maior frequência de frases apresenta é o PCP com 430, seguido do PS com 308 frases. O último lugar, no conjunto dos partidos políticos, neste ano, é assumido pelo $\mathrm{BE}$, com apenas 46 frases.

No período eleitoral do ano de 2002, o primeiro lugar é assumido pelo PS com 304 frases, o segundo pelo PCP com 281 frases. Neste ano, a derradeira posição é representada pelo PSD (102 frases). Cabe aqui evidenciar que no presente ato eleitoral o BE não foi considerado pela indisponibilidade de programa eleitoral anotado/ codificado.

As posições do PCP e PS mantêm-se no ano eleitoral de 2005, com 274 e 247, respetivamente, seguido do $\mathrm{BE}$ com 182 frases. Uma vez mais, as últimas posições são preenchidas pelo PSD e CDS/PP (90 e 59 frases, respetivamente).

Curiosamente, no ato eleitoral de 2011 as posições invertem-se claramente com o BE a ocupar a primeira posição (186 frases), seguido do PSD com 145 e CDS/PP com 116 frases. O PCP e o PS representam neste ano eleitoral os últimos lugares, com 13 e 76 frases, respetivamente.

Este comportamento poderá denotar uma certa cumplicidade por opções políticas que porventura não foram as mais adequadas do ponto de vista económico. Como o PS assumiu entre 1999 e 2011 um maior período na governação do país percebe-se que haja uma certa tendência de redução dos investimentos na componente social, em detrimento do imperativo cumprimento das metas orçamentais impostas pelo projeto europeu.

A redução do número de frases no programa eleitoral do PCP, em 2011, poderá igualmente ser sintoma do reconhecimento da fragilidade das contas públicas do país, sem prejuízo de outras interpretações.

O PSD e o CDS/PP exibem algumas oscilações ao longo do tempo. Ainda assim, o PSD concentra maior preocupação com a expansão do Estado social no ato eleitoral de 2011, seguido do CDS/PP, cujo número de frases sofre uma evolução favorável por relação ao ato eleitoral anterior (59 e 116). Esta situação poderá eventualmente estar relacionada com uma maior preocupação de ascender ao poder político, uma vez que de 1999 a 2011 o PSD apenas esteve ao leme do país entre 2002 e 2005.

4. Partido Social Democrata (PSD); Partido Socialista (PS); Bloco de Esquerda (BE); Centro Democrata-Social/ Partido Popular (CDS/PP); Partido Comunista Português (PCP).

5. Os Programas Eleitorais do ano de 2009 não foram anotados e, como tal, não avaliados no presente estudo. 
Do conjunto da informação, ressalta que o BE foi ao longo dos quatro anos eleitorais a única força política que seguiu um caminho de ascensão relativamente ao número de frases, com 46, 182 e 186.

Contrariamente, o PCP e o PS fizeram um percurso inverso, sendo que com o evoluir dos anos a preocupação com o Estado social parece declinar, muito provavelmente pelos motivos já expostos.

As duas forças políticas que em 1999 detinham a supremacia nesta matéria (PS e PCP) são aquelas que, de forma ininterrupta, mantêm a maior tendência de declínio ao longo dos períodos eleitorais observados, atingindo a sua minorada expressão em 2011.

Da representação gráfica extrai-se uma outra apreciação relacionada com a contração de políticas promotoras do Estado social que, cada vez mais, abandonam os compromissos políticos. De facto, com o evoluir dos anos, e com eles os diferentes atos eleitorais, verifica-se, genericamente, um decréscimo do número de frases relacionadas com a expansão do Estado de bem-estar, situação que parece encontrar justificação na degradação crescente das finanças públicas e fraco desenvolvimento económico do país, relegando para um plano menor a questão do Estado social.

\section{Gráfico 2}

Número de frases categorizadas com o código 504 (Expansão do Estado de Bem-estar)

Referência às Pessoas Idosas - Atos Eleitorais/Partidos Políticos

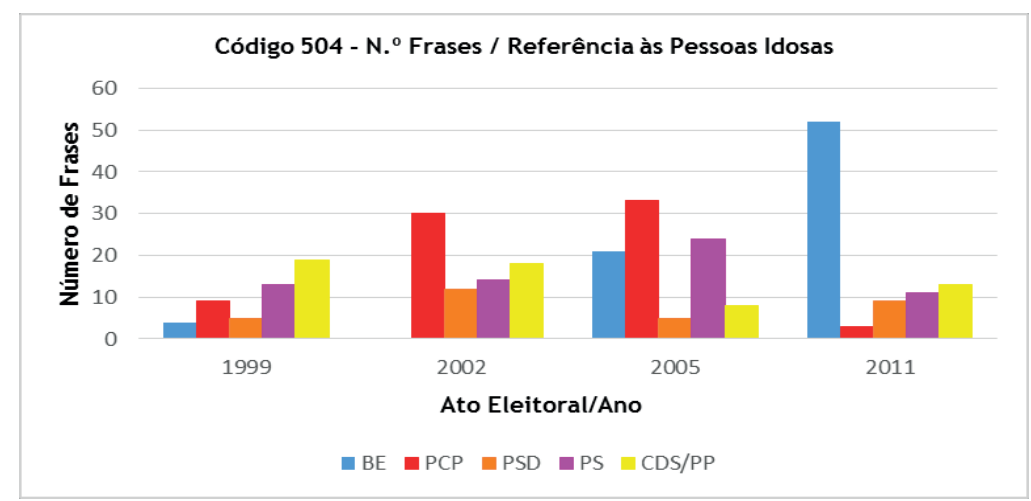

Fonte: Elaboração própria com base nos dados do Manifesto Project.

O gráfico demonstra que entre o ano de 1999 e 2002, e porque o BE não deverá ser considerado pelo motivo já exposto, todas as forças políticas, à exceção do CDS/PP que exibe uma ligeira diminuição (19 para 18), expõem um crescendo relativamente 
à preocupação com as pessoas idosas. Todavia, em 2005, esta tendência é mantida pelo PS, PCP e BE, com 33, 24 e 21 frases, respetivamente, que contrapõe com o declínio do CDS/PP e PSD, dados que transparecem uma orientação visivelmente oposta (8 e 5 frases, respetivamente).

Em 2011, o PCP e PS exibem uma queda neste domínio, contrariando fortemente a tendência até aqui verificada. Destaca-se, neste âmbito, o BE, ao distanciar-se das restantes forças políticas, demonstrando um aumento da valorização dos idosos neste ano eleitoral. Igual tendência de subida é evidenciada pelo PSD e CDS/PP.

A análise desta inflexão da tendência verificada pelo PSD, no programa eleitoral do ano de 2005, poderá encontrar algum fundamento na perceção que o partido adquiriu sobre a fragilidade das contas públicas, no período em que governou o país (2002-2005).

A descida evidenciada contrapõe claramente com a tendência de subida verificada no programa eleitoral de 2011, quer do PSD, quer do CDS/PP. No contexto do supra descrito, esta informação poderá sugerir uma tentativa de agradar ao eleitorado/pessoas idosas, grupo de relevo no seio dos eleitores.

A redução do número de frases em apreço, verificada nos programas eleitorais do PS e PCP em 2011, terá eventual justificação à luz dos constrangimentos económicos e financeiros da crise iniciada em 2007/2008.

\subsection{Portugal - A retração do Estado de bem-estar}

\section{Gráfico 3}

Número de frases categorizadas com o código 505 (Retração do Estado de Bem-estar) Atos Eleitorais/Partidos Políticos

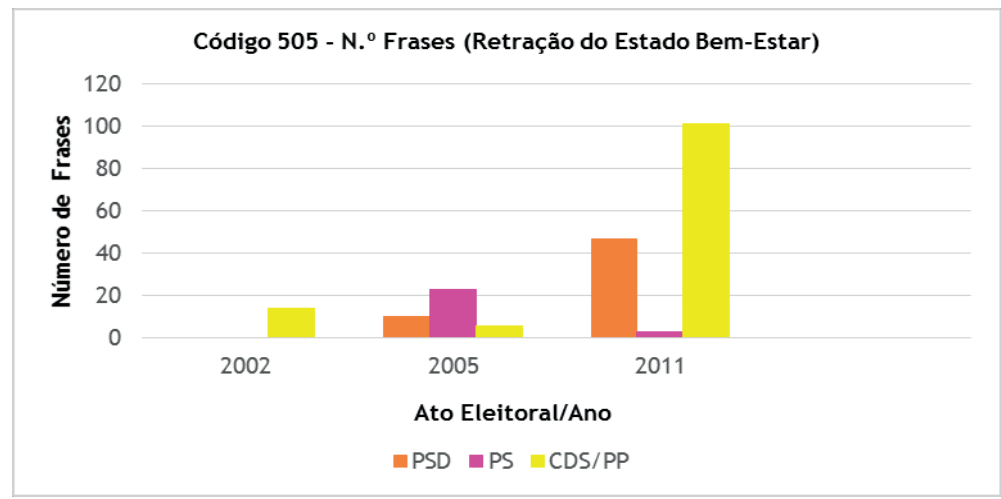

Fonte: Elaboração própria com base nos dados do Manifesto Project. 
Das três forças políticas, cujos programas eleitorais integram frases categorizadas com o código 505, a partir do ano eleitoral de 2005 há uma inversão das tendências verificadas no período eleitoral antecedente (2002). De facto, os valores nulos registados pelo PSD e PS em 2002 passam a positivos em 2005, com 10 e 23 frases, respetivamente, por oposição ao CDS/PP, única força que em 2002 regista valores positivos (14 frases), pese o decréscimo verificado em 2005 (6 frases).

Nas eleições do ano de 2011, as duas forças políticas de direita (PSD e CDS/PP) assinalam um aumento muito expressivo neste domínio com 47 e 101 frases, respetivamente. A esquerda, aqui representada pelo PS, exibe uma diminuição do número de frases categorizadas com o código 505 (3 frases).

Daqui se pode inferir que são as forças de direita a assumir a dianteira no campo da retração do Estado social, por oposição às forças de esquerda, algumas das quais (PCP e BE) sem qualquer representação neste campo nos seus manifestos eleitorais.

\section{Gráfico 4}

Número de frases categorizadas com o código 505 (Retração do Estado de Bem-estar) Referência às Pessoas Idosas - Atos Eleitorais/Partidos Políticos

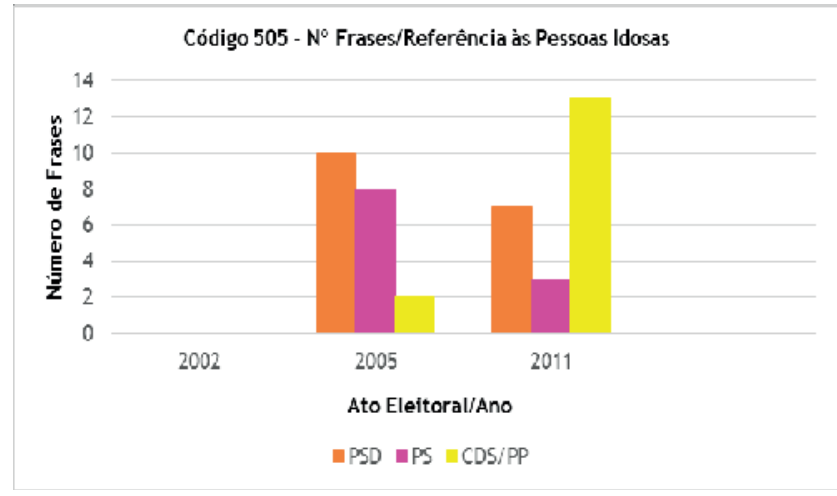

Fonte: Elaboração própria com base nos dados do Manifesto Project.

A ascensão assumida pelo PSD e PS nas eleições de 2005 contrasta com a redução do número de frases alusivas à população idosa verificada nos seus programas eleitorais do ano de 2011. Relativamente à restante força política, CDS/PP, sem representação neste domínio no programa eleitoral do ano de 2002, apresenta uma clara tendência de subida, que inicia em 2005 com 2 frases, aumentando para 13 em 2011.

Ao que parece, as duas forças políticas mais votadas em Portugal (PSD e PS) apresentam-se às eleições do ano de 2011 sem querer atentar, de forma muito expressiva, sobre um grupo etário vulnerável que poderá fazer a diferença nos resultados eleitorais. 


\subsection{A posição dos partidos políticos na escala esquerda/direita (Rile)}

\section{Gráfico 5}

Posição dos partidos políticos na escala esquerda/direita - Rile (1995-2011)

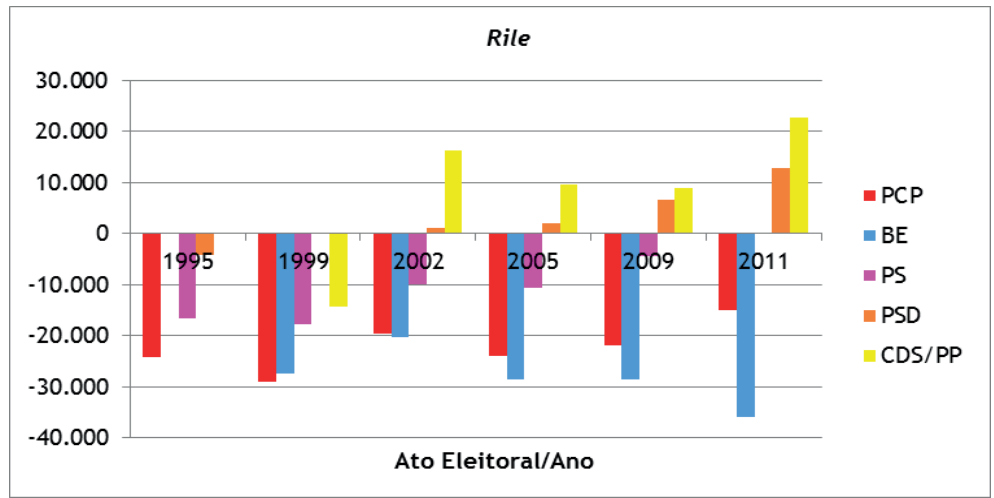

Fonte: Elaboração própria com base nos dados do Manifesto Project.

O gráfico demonstra que nos períodos eleitorais de 1995 e 1999 duas forças de direita partilham a posição ideológica de esquerda, PSD e CDS/PP, respetivamente. A partir de 2002, ambos os partidos apresentam valores positivos, definindo, expressamente, o seu campo ideológico com posicionamento de direita.

Por oposição, ao longo dos atos eleitorais analisados, os partidos tradicionalmente posicionadas à esquerda mantêm-se fiéis à respetiva área ideológica, com valores negativos, apesar de existir uma certa tendência, a partir do ano de 2002, de aproximação do centro da escala por parte do PS, atingindo mesmo em $2011 \mathrm{um}$ valor positivo (0.241), ainda que não seja percetível no gráfico.

Esta informação contrasta com o posicionamento do PSD que a partir do ano de 2005 exibe uma tendência gradual de afastamento do centro da escala, rumo a uma cada vez maior consolidação da sua área ideológica. O CSD/PP revela igual tendência a partir do ano de 2009, sem prejuízo do resultado revelado no ano de 2002, significativamente acima dos anos eleitorais de 2005 e 2009. Ainda assim, a sua posição demarca-se bastante do centro da escala no ano de 2011.

A partir do ato eleitoral do ano de 2005, a única força política que segue um percurso de afastamento progressivo e acentuado do centro da escala, com posicionamento de esquerda, é o BE.

Será de registar, também, o posicionamento do PCP com uma progressiva propensão, a partir do ano de 2005, de inversão do sentido até ali verificado. 


\subsection{Nível de defesa do Estado de bem-estar em Portugal}

\section{Gráfico 6}

Nível de Defesa do Estado de Bem-estar (Welfare State) (1995-2011)

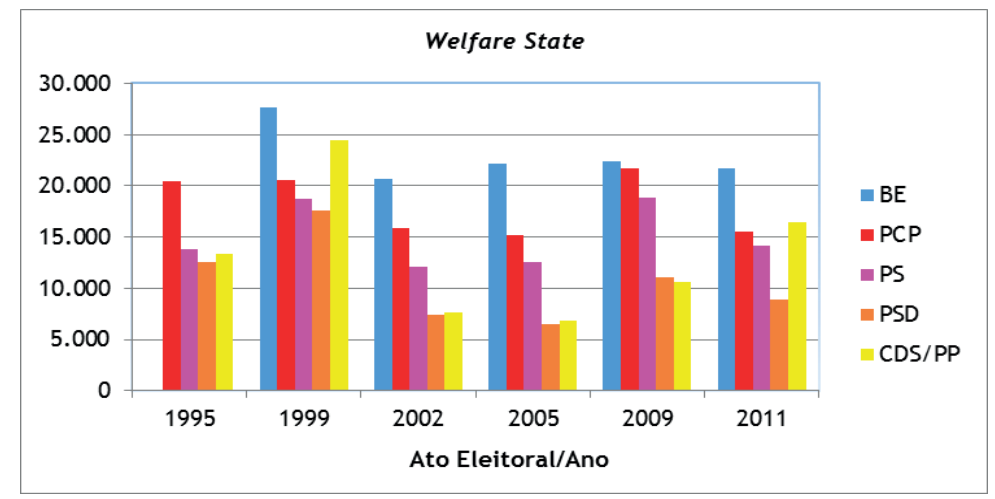

Fonte: Elaboração própria com base nos dados do Manifesto Project.

No conjunto das forças políticas em presença, o gráfico revela que no ato eleitoral de 1995 o destaque é assumido pelo PCP com um nível de defesa do Estado social (20.496) acima de qualquer outra força política. ${ }^{6}$ Nas eleições subsequentes (1999, 2002, 2005, 2009 e 2011), a força política que maior representação detém na proteção do Estado social é o BE. Por outro lado, à exceção do ano de 1999 e 2011 (CDS/ $\mathrm{PP}$ ), os partidos que menor nível de defesa exibem são aqueles que se posicionam no campo ideológico de direita.

Em termos gerais, no que concerne às tendências observadas, cabe registar que as forças políticas BE e PCP tendem a diminuir os níveis de defesa do Estado social, situação acompanhada pelas forças de direita PSD e CDS/PP. Contrariamente, o PS tende a manter, ou mesmo elevar, ainda que muito ligeiramente, o seu nível de defesa do Estado social.

Estabelecendo uma comparação entre o presente gráfico e o anterior (Rile), é oportuno referir que embora o PS tenda, ao longo dos anos, a aproximar-se do centro da escala é, por sua vez, a única força política que mantém estáveis os níveis de proteção social. As outras duas forças políticas de esquerda (PCP e BE), embora afirmando o seu posicionamento à esquerda, tendem a diminuir o seu grau de proteção do Estado social. 
Quanto às forças políticas de direita (PSD e CDS/PP), cujo afastamento do centro da escala esquerda-direita é crescentemente notório, o seu discurso programático é cada vez mais recheado de frases que indiciam a adoção de políticas que inferem uma paulatina retirada do Estado na proteção social.

\subsection{Espanha - A expansão do Estado de bem-estar}

\section{Gráfico 7}

Expansão do Estado de Bem-estar - Referências favoráveis à sua defesa Atos Eleitorais/Partidos Políticos

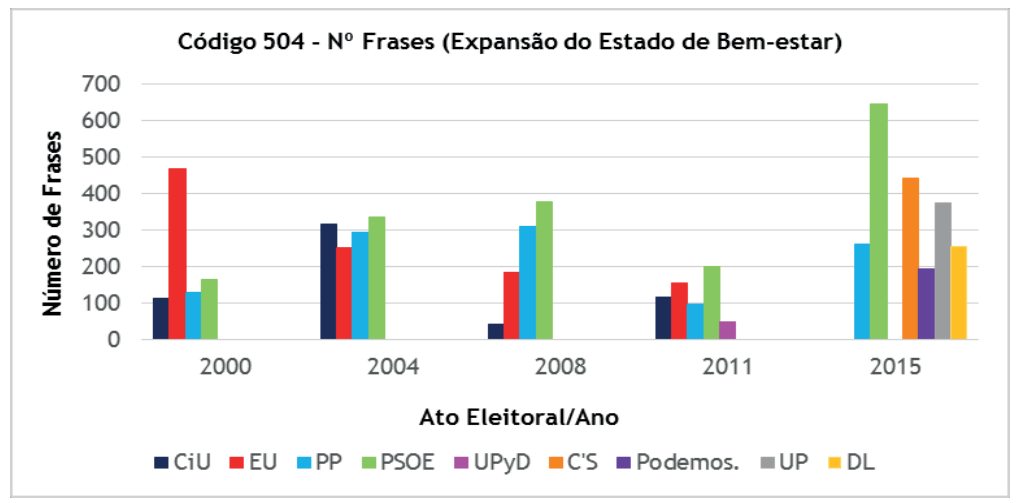

Fonte: Elaboração própria com base nos dados do Manifesto Project.

A apresentação gráfica revela, no conjunto dos partidos políticos ${ }^{7}$, que no ato eleitoral do ano de 2000 apenas a força política Esquerda Unida (EU) se destaca pela atenção atribuída à expansão do Estado de bem-estar. Os restantes partidos (PSOE, $\mathrm{PP}$ e $\mathrm{CiU}$ ) exibem valores aproximados, sobressaindo, ainda assim, o PSOE.

Nas eleições de 2004, os resultados invertem-se com a EU a assumir menor realce, exibindo até uma certa inflexão nos resultados por relação às restantes forças políticas, as quais fizeram um trajeto de ascensão no domínio em análise.

No ato eleitoral do ano de 2008 assiste-se ao predomínio do PSOE sobre as restantes forças políticas, seguido do PP, ambos com um percurso de ascensão em ter-

7. Convergência e União (CiU); Partido Popular (PP); Partido Socialista Obreiro Espanhol (PSOE); União, Progresso e Democracia (UPyD); Cidadãos (C's); Podemos (Podemos.); Unidade Popular (UP) e Democracia e Liberdade (DL). 
mos de ostentação de frases alusivas à expansão do Estado social. As forças políticas restantes sofreram um decréscimo por relação ao ato eleitoral anterior, com particular expressividade o partido CiU (de 317 para 40).

Em 2011, o PSOE e o PP contrariam a tendência verificada no ato eleitoral precedente, expondo uma descida acentuada em termos do número de frases. Igual diminuição é patenteada pela EU (183, contra 153). O partido político CiU exibe neste ato eleitoral uma subida digna de registo, de 40 para 116 frases. Neste período eleitoral surge ainda o resultado de um partido fundado mais recentemente, UPyD, exibindo 47 frases.

Nas eleições de 2015, ano em que não é possível avaliar o CiU (dissolvido em junho deste ano e antecessor da força política DL) e o EU (partido que integrou a coligação UP neste ano), entram em jogo as mais jovens forças políticas, algumas das quais com uma frequência digna de notação, nomeadamente o C'S com 441 frases, UP com 373 e DL com 254, ainda assim valores inferiores ao apresentado pelo PSOE (644), o indicador mais elevado no conjunto dos períodos eleitorais estudados. Neste mesmo período, o PP surge com 260 frases e o Podemos com 193.

\section{Gráfico 8}

Número de frases categorizadas com o código 504 (Expansão do Estado de Bem-estar) - Referência às Pessoas Idosas - Atos Eleitorais/Partidos Políticos

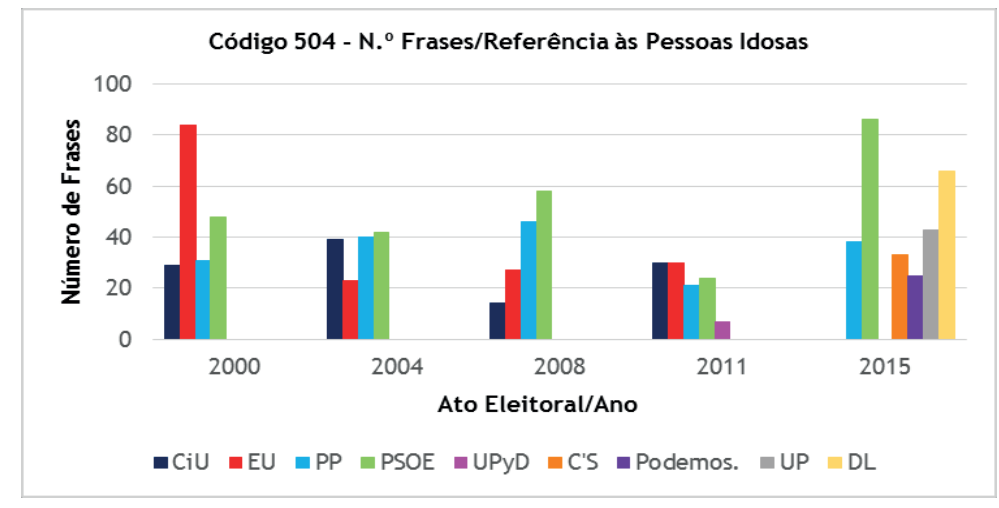

Fonte: Elaboração própria com base nos dados do Manifesto Project.

O gráfico revela que a força política que mais se evidencia no ato eleitoral do ano de 2000 é a EU (84 frases), seguida do PSOE (48) e, nos últimos lugares, o PP (31) e CiU (29). No período eleitoral posterior, o destaque é assumido pelo PSOE (42), seguido do PP (40), CiU (39) e, com menor frequência, a EU (23). 
Os programas eleitorais referentes às eleições de 2008 não alteram as primeiras posições alcançadas no ano de 2004, dado que o destaque volta a ser assumido pelo PSOE com 58 frases, seguido do PP com 46 e, nas posições inferiores, a EU com 27 e o CiU com 14. Porém, as posições cimeiras ocupadas pelo PSOE e PP em 2004 e 2008 alteram-se em 2011, tendo sido substituídas pelo CiU e EU, ambos com 30 frases alusivas à população idosa. Na derradeira posição fica o UPyD com apenas 7 frases neste âmbito.

No ato eleitoral de 2015, num conjunto mais amplo de partidos ${ }^{8}$, o PSOE volta a recuperar a sua colocação com 86 frases, seguido da DL com 66, UP com 43, PP com 39, C'S com 32 e, no extremo desta escala valorativa, o Podemos com 25 frases alusivas à população idosa.

\subsection{Espanha - A retração do Estado de bem-estar}

\section{Gráfico 9}

Número de frases categorizadas com o código 505 (Retração do Estado de Bem-estar) Atos Eleitorais/Partidos Políticos

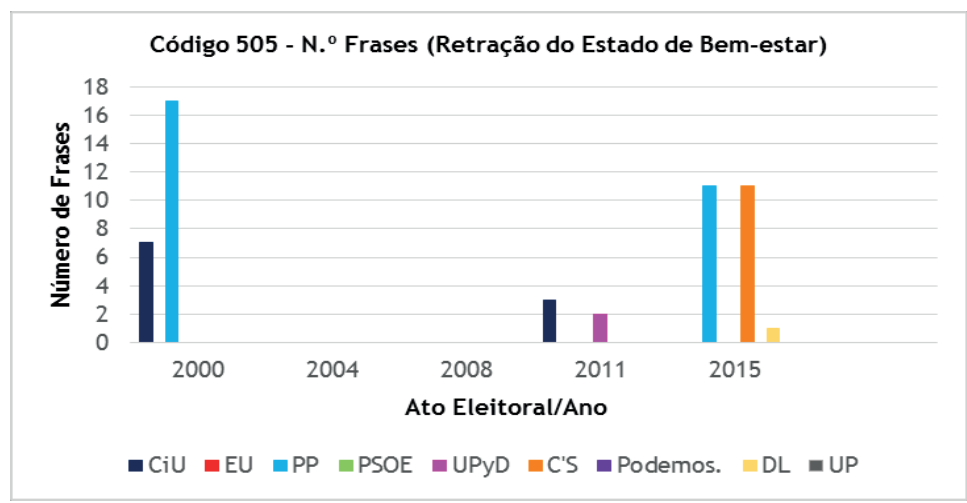

Fonte: Elaboração própria com base nos dados do Manifesto Project.

A defesa pela retração do Estado de bem-estar assume especial destaque em dois períodos eleitorais, nomeadamente o ano de 2000 e 2015. No primeiro ano registado, o PP assume o protagonismo por relação ao CiU, únicas forças políticas representadas neste campo. No ano eleitoral de 2015, o destaque é apropriado, em exequo, pelo PP e C'S. Em último lugar, de forma quase inexpressiva, surge representada a força política DL. 


\section{Gráfico 10}

Número de frases categorizadas com o código 505 (Retração do Estado de Bem-estar) Referência às Pessoas Idosas - Atos Eleitorais/Partidos Políticos

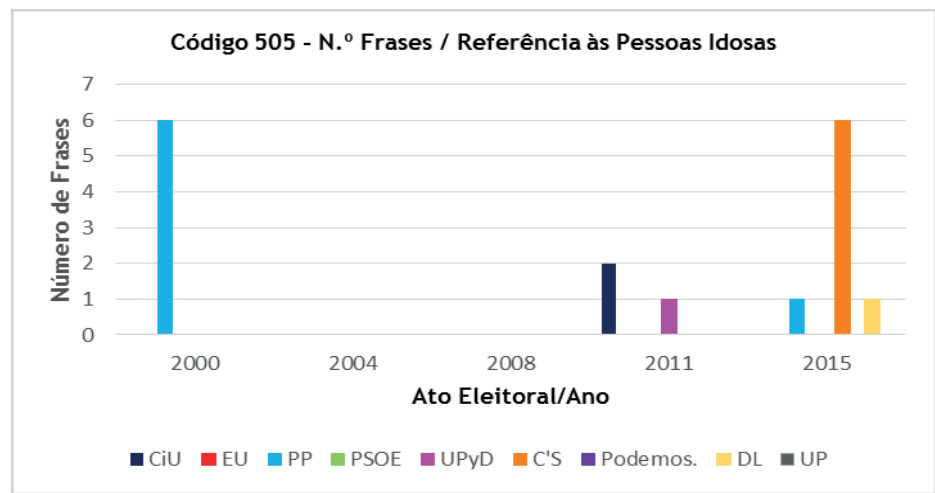

Fonte: Elaboração própria com base nos dados do Manifesto Project.

No campo da retração do Estado social e por relação às pessoas idosas, o PP e o C'S recolhem o protagonismo. No entanto, o PP tem uma representação isolada no ato eleitoral de 2000, sendo relegado para segundo plano no ano de 2015, cuja dianteira é assumida pela força política C'S. Em 2011, embora sem grande expressividade, surgem como defensores da retração do Estado de bem-estar o CiU e o UPyD.

\subsection{A posição dos partidos políticos na escala esquerda/direita (Rile)}

\section{Gráfico 11}

Posição dos partidos políticos na escala esquerda/direita - Rile (2000-2015)

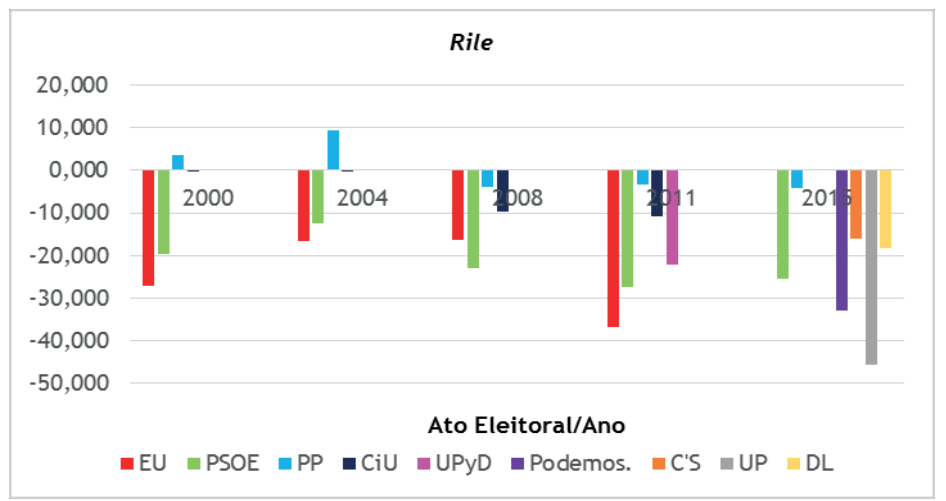

Fonte: Elaboração própria com base nos dados do Manifesto Project. 
Nos períodos eleitorais em análise, a larga maioria dos partidos em presença posiciona-se ideologicamente à esquerda, mesmo aqueles que tradicionalmente assumem uma posição de centro a centro-direita. Efetivamente, o PP que em 2000 e 2004 ocupa um espaço leal à sua ideologia de base passa, a partir do ano de 2008, a partilhar o campo ideológico de esquerda, embora com um percurso muito contíguo ao centro da escala.

O gráfico informa ainda que no ano de 2000, 2004 e 2011 a EU é a força política que maior expressividade assume na posição ideológica de esquerda, num comportamento de fidelidade com o seu espaço ideológico, seguida do PSOE, partido ideologicamente de centro-esquerda.

Em 2015, o protagonismo neste domínio é alcançado pela força política UP, seguida, em ordem decrescente, pelo Podemos, PSOE, DL e C'S, revelando, deste modo, maior afirmação no espaço ideológico de esquerda. Curiosamente, os C’S, força que se assume ideologicamente do centro, apresenta um posicionamento à esquerda, algo distante do centro da escala esquerda-direita.

É digno registar que a partir do ano eleitoral de 2004 todas as forças políticas assumidas de centro e centro-direita comungam o espaço ideológico de esquerda, numa tendência de afastamento cada vez mais pronunciado do centro da escala, de forma mais vincada a partir do ano de 2008.

\subsection{Nível de defesa do Estado de bem-estar em Espanha}

Gráfico 12

Nível de Defesa do Estado de Bem-estar (Welfare State) (2000-2015)

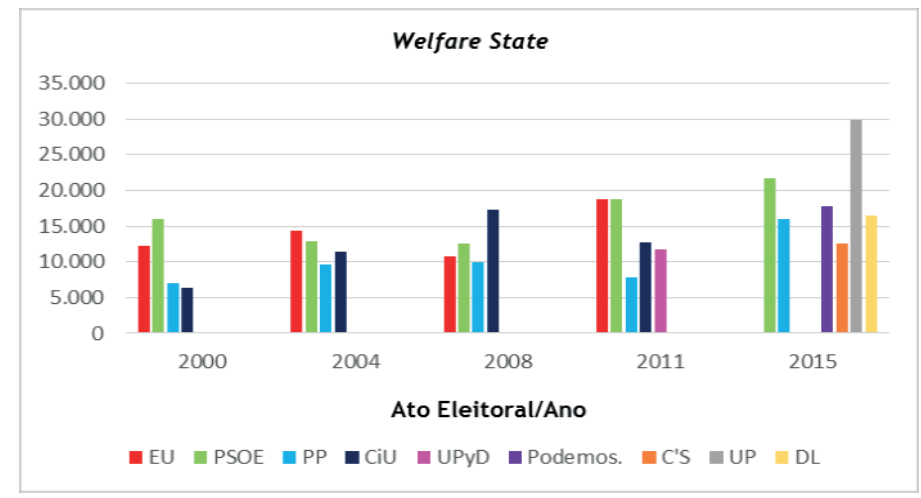

Fonte: Elaboração própria com base nos dados do Manifesto Project. 
Extrai-se da representação gráfica que entre o período eleitoral de 2000 e 2011, à exceção do ano de 2008, existe uma prevalência de defesa do Estado de bem-estar assumida, maioritariamente, pelas forças políticas mais à esquerda, nomeadamente pela EU (esquerda) e PSOE (centro-esquerda). A exceção é verificada no ano de 2008, período em que o $\mathrm{CiU}$ assume a predominância.

No ato eleitoral de 2015 verificam-se níveis de defesa do Estado de bem-estar nunca antes atingidos, com especial supremacia por parte da força política UP, seguido do PSOE e Podemos.

Em termos gerais, tendo em consideração os partidos que permitem uma avaliação da tendência, todas as fações políticas tendem a aumentar os seus níveis de defesa do Estado social, informação que está em linha com o Rile de cada um dos partidos políticos (valores negativos), pese a aproximação do PP ao centro da escala.

\section{Síntese dos principais resultados da análise qualitativa - Comparação Por- tugal Espanha}

Tal como se referiu anteriormente, após a extração das frases dos manifestos eleitorais estudou-se o seu conteúdo, tendo sido criadas diversas categorias a partir das mesmas. Dada a dimensão desta avaliação, resultante da extensão dos documentos em apreço ${ }^{9}$, apresenta-se, de seguida, uma síntese dos resultados obtidos, quer no domínio da expansão, quer da retração do Estado de bem-estar.

Expansão e retração do Estado de bem-estar - Temas abordados nos manifestos eleitorais dos partidos políticos em ambos os países

Dentro da área de expansão do Estado social, um olhar comparativo aos países avaliados permite constatar uma grande transversalidade dos temas abordados. Com efeito, o tema pensões, equipamentos sociais/respostas sociais, família, saúde, terceira idade, segurança social/sustentabilidade, demografia, terceiro setor, reforma parcial/trabalho parcial/flexibilidade da idade de acesso à reforma e, ainda, os planos ou fundos de pensões constituem categorias comuns, embora, por vezes, detenham uma designação ligeiramente diferente. Excluem-se deste tratamento comum as categorias habitação e dependência, cujo destaque surge pela via da insistência com que aparecem nos programas eleitorais das forças políticas espanholas.

Cabe igualmente registar, pela importância que detém no seio das sociedades atuais, que a questão do envelhecimento ativo, dentro da perspetiva em foco, somente é incluída nos manifestos eleitorais de Espanha. Portugal alude a este tema apenas na ótica da retração do Estado social, enquanto forma de evitar a perda de competências e minimizar os custos da antecipação da idade da reforma. 
Esta informação leva-nos a concluir que as preocupações, em torno da expansão do Estado de bem-estar, são bastantes similares nos dois países.

Quanto à área de retração do Estado social, enquanto em Espanha se focaliza a categoria segurança social - sustentabilidade do sistema, planos ou fundos de pensões/pensões complementares, na perspetiva da sua promoção, em Portugal alude-se à necessidade de reformar o sistema de pensões, implementando novas regras de acesso, limitação dos montantes, diversificação das fontes de financiamento e incentivo à criação de esquemas complementares de proteção social, a par, também, da reforma parcial, trabalho parcial, flexibilização da idade de acesso à reforma e envelhecimento ativo (evitar perda de competências e minimizar custos da antecipação da idade da reforma).

Neste contexto, não se pode afirmar com convicção que o tratamento deste tema detém significados distintos em ambos os países, porquanto pode tratar-se apenas da atribuição de maior ou menor pormenor na descrição do mesmo. De facto, a questão da sustentabilidade da segurança social, planos ou fundos de pensões/pensões complementares pode ter na sua base a necessidade de encontrar formas de reduzir despesas com a proteção social, seja a implementação de novas regras de acesso às pensões, mais penosas portanto, seja a limitação dos montantes, entre outras.

O desafio da sustentabilidade da segurança social vale para ambos os países, ${ }^{10}$ tendo vindo a ganhar destaque face à confluência de vários fatores, entre os quais sobressaem as transformações no mercado de trabalho, a organização da vida familiar, a esperança média de vida, a situação das finanças públicas, alguns dos quais com efeito sistémico.

A questão do terceiro setor também é partilhada por ambos os países nesta perspetiva de retração do Estado social. Em Espanha fala-se no estabelecimento de alianças neste âmbito para a prestação de serviços de saúde, posição que parece ser reforçada pela categoria «Promoção de planos privados de Saúde”. Em Portugal, esta questão é apresentada de outro modo através das categorias: «Equipamentos Sociais transferência de equipamentos sociais geridos pelo Estado para as Instituições Particulares de Solidariedade Social (IPSS)» e Equipamentos Sociais (Desenvolvimento/reforço da parceria e apoio financeiro às IPSS/autossuficiência futura das IPSS). Relativamente à primeira, a intenção/compromisso patente no programa eleitoral da força política CDS/PP acabou por se concretizar em 2015 pela mão de um governo de coligação PSD e CDS/PP, suportada na iniciativa legislativa expressa no Decreto-Lei n. ${ }^{\circ}$ 240/2015, de 14 de outubro. Quanto à segunda categoria é possível afirmar que as intenções patentes nos discursos programáticos deixam antever a transferência de responsabilidades, tradicionalmente na esfera do Estado, para as IPSS, constituindo exemplo a criação da Rede Local de Intervenção Social (RLIS), os Protocolos do Rendimento Social de Inser- 
ção (RSI) e a Linha de Emergência Social (144), equipas já implementadas no território continental, tendo em vista o acompanhamento de indivíduos e famílias em situação de vulnerabilidade económico-social.

A relação entre o Rile e o Welfare- state de cada partido político, em ambos os países

Ao estabelecer a comparação entre o Rile e o nível de defesa do Estado social (Welfare State) de cada um dos países avaliados, verifica-se:

Em Portugal:

- Ao afastamento positivo do centro da escala esquerda-direita corresponde uma diminuição dos níveis de proteção social, com exceção de uma única força política de esquerda (PS), cuja defesa do Estado social se mantém estável ao longo dos períodos eleitorais analisados, não obstante a sua aproximação cada vez mais pronunciada do centro da escala em apreço.

- Ao afastamento negativo do centro da escala esquerda-direita não corresponde um aumento dos níveis de defesa do Estado social.

Em Espanha:

- Ao afastamento positivo, ainda que muito próximo do centro da escala esquerda-direita (situação verificada apenas com o partido político PP), corresponde um nível, ainda que baixo, de defesa do Estado social;

- Ao afastamento negativo do centro da escala esquerda-direita corresponde um aumento dos níveis de defesa do Estado social, sendo que quanto mais afastadas as forças políticas estão do centro da escala, maiores níveis de defesa do Estado social exibem.

\section{Principais conclusões}

Em face do apurado, em termos globais, em ambos os países, a esquerda (Portugal) e esquerda/centro-esquerda (Espanha) assumem a preponderância na defesa da expansão do Estado de bem-estar e população idosa, por oposição aos partidos do centro/centro-direita que evidenciam uma orientação menos propugnadora neste campo.

No domínio da retração do Estado social, incluindo a população idosa, igualmente de modo geral, o destaque é assumido, nos dois países, pelas forças de centro/centro-direita. Cabe registar que os manifestos eleitorais das forças políticas estudadas começam a abordar a retração do Estado social, mediante a inclusão de frases categorizadas com o código 505, a partir do ano eleitoral de 2000 no caso de Espanha e em 2002 no caso de Portugal, em ambos os casos pela mão do centro/centro-direita. No entanto, em Portu- 
gal assiste-se a um aumento significativo destas frases no ano eleitoral de 2011, situação que poderá estar relacionada com a existência de um contexto fraturante causado pelos baixos índices de desenvolvimento e crescimento económico do país que, com o decorrer dos anos, se foi agravando, a par dos fatores exógenos (crise económico-financeira) e endógenos (conflitos entre órgãos de soberania) à governação do país que determinaram a substituição inesperada do governo (demissão do primeiro-ministro).

As categorias tratadas em ambos os países assemelham-se às peças de um puzzle, por vezes com um efeito sistémico, que começa com a alteração do modelo de família tradicional, passando pelo aumento da esperança de vida e consequente envelhecimento demográfico, cujos resultados diretos determinam a criação de estruturas de apoio aos idosos e, mais recentemente, a tendência para investir na promoção de políticas de envelhecimento ativo. Trata-se de uma lógica de prolongamento da vida ativa, com evidentes benefícios para os próprios e entidades empregadoras e, por último, mas não menos importante, o equilíbrio do sistema de proteção social.

Por fim, importa referir que a conjuntura económica e política, patente em determinado país e período eleitoral, poderá ser crucial para influenciar ou condicionar as opções políticas relativas à defesa de determinadas matérias estruturantes para o futuro. Por outro lado, sendo os programas eleitorais declarações oficiais das forças políticas, em presença num palco eleitoral, a sua elaboração está fortemente subordinada ao ambiente político, cultural, económico e social patente num determinado confronto eleitoral.

\section{Bibliografia}

ALONSO, Sonia, Andrea VOLKENS e Braulio GOMEZ (2012) Análisis de contenido de textos políticos. Un enfoque cuantitativo. Cuadernos metodológicos. Madrid: Centro de Investigaciones Sociológicas.

ARES CASTRO-CONDE, Cristina (2018) «Envejecimiento y política: un debate politológico”. Revista de Estudios Políticos, 179, 171-198. doi: https://doi. org/10.18042/cepc/rep.179.06.

DEL PINO, Eloísa e Maria J. R. LARA (2013) (Eds.) Los Estados de Bienestar en la encrucijada - Politicas Sociales em Perspectiva Comparada. Editorial Tecnos.

EQUIPO NORSPAR (2015) «Los nuevos riesgos sociales y las reformas del Estado de Bienestar", en Francisco Javier Moreno Fuentes, Eloísa Del Pino Matute (Coords.) Desafíos del Estado de bienestar en Noruega y España, Nuevas políticas para atender a nuevos riesgos sociales. Madrid: Editorial Tecnos.

MORENO, Luis (2012) Crisis y estado del bienestar - la europa asocial, caminhamos hacia un individualismo posesivo? Barcelona: Ediciones Península.

\section{Base de dados}

Manifestoproject.wzb.eu

https:/visuals.manifesto-project.wzb.eu/mpdb-shiny/cmp_dashboard_dataset/ 